\title{
The affective dimension of alliance in transactional analysis psychotherapy
}

\section{(C) 2010 Roland Johnsson and Gunvor Stenlund}

\begin{abstract}
The study describes an investigation of the significance of the affective dimension of the therapeutic alliance (Bordin 1979), in a psychodynamic form of transactional analysis therapy after the style of "Redecision therapy" (Goulding \& Goulding, 1979). We explored the client's pattern of affective relationships by use of CCRT (the Core Conflictual Relationship method, Luborsky \& CritsChristoph, 1990, 1998) and examined how the therapist responds to the client's affective messages ("tests") by use of the Plan Diagnosis method (Weiss \& Sampson, 1986). We found that "emotional" aspects play a more decisive role than has been envisioned in the TA redecision method and similar approaches of TA psychotherapy that emphasise contracts, tasks of therapy and a rational approach.
\end{abstract}

\section{Key words}

alliance, transactional analysis psychotherapy (TA), process research, affective communication, CCRT, therapeutic relationship.

\section{Background to the Study}

In psychotherapy research, interest has been shown in identifying process variables that affect the therapeutic outcome (Hill \& Lambert, 2004). These include both variables having specific effects consistent with the theory of the therapy involved and variables having effects common to most forms of therapy. The latter, termed "common factors" (or sometimes non-specific factors), are seen as having general curative effects (Wampold, 2001) that influence the outcome in a positive direction (Lamberts \& Ogles, 2004). How they are defined is by no means universal, however. Lamberts and Ogles link such effects to factors in the therapeutic relationship. The therapist "invites" the client to "believe" both in their working together toward solving the client's problems and in the efficacy of the methods employed.

Carl Rogers (1961) has described such factors as genuineness, acceptance and empathy, which he sees as being conductive to establishing a therapeutic relationship. Jerome Frank has emphasized the importance of the therapist's ability to "convince" the client (Frank \& Frank, 1991). One factor often studied, which applies to the therapeutic relationship generally, is that of "alliance". Two large metastudies (Horvath \& Bedi, 2002; Horvath \& Symonds, 1991) have shown a link between alliance and positive results of therapy. Although transactional analysis psychotherapy was not examined, we assume this would apply to that method as well.

\section{The concept of alliance}

The concept of alliance is often used to denote a close working relationship between the client and the therapist. Despite the concept being anchored within most forms of psychotherapy, there is no universal definition of it. Views regarding the question of whether alliance is a rational or an emotional phenomenon differ (Henry, Strupp, Schacht \& Gaston, 1994). These authors emphasize the importance of anchoring the concept within a theoretical frame of reference. With this in mind, Stenlund (2002) investigated use of the term in both a theoretical and an empirical sense within the psychoanalytic and the psychodynamic tradition. Her findings suggest that alliance can be defined in affecttheoretical terms (Tomkins, 1962, 1963 1991, 1992).

In the present study we decided to adopt such an approach, viewing alliance as being primarily an affective phenomenon reflecting the relationship between the client and the therapist. The affective communication involved - how the therapist responds to affective messages from the client - is thus a central 
interest of ours, determining how we investigate alliance and its development in the course of the therapeutic relationship.

The alliance concept in transactional analysis group therapy

Transactional analysis (TA) originated in the works of Eric Berne (Berne, 1958, 1961, 1963, 1964, 1966, 1972), in which the "official" theory and the therapeutic approach and methods were described. Since then, various schools have developed within the framework Berne established. The form of transactional analysis group therapy studied here is one consistent with the "Redecision Therapy" described by Goulding and Goulding (1979). The approach can be described as involving individual therapy in a group in which interaction takes place primarily between the client and the therapist with the group mainly providing support.

In this form of group therapy the therapist does not work directly with transference. Instead reduction of transference is sought through use of different experiential directive techniques such as experimenting tasks, role-play and "two-chair work". The last mentioned technique (Goulding \& Goulding, 1979) involves contracting with the client to regress to an earlier stage in his/her life to re-experience a conflict-filled situation together with a parental figure he imagines to be present and to be sitting in a chair facing the client, this being the basis for use of the term "two-chair". The resulting discussion between "chair characters" is seen as creating new possibilities for curative changes to develop. In a variety of studies of Gestalt therapy (e.g. Clarke \& Greenberg, 1986; Greenberg, Rice \& Lietaer, 1993), this two-chair approach has been shown to deepen the emotional understanding of the client. Regression of this sort differs from the spontaneous type that comes about when the therapist listens and develops a "holding relationship" with the client (Lundh, 2009). These two different routes to regression-work (Ohlsson, 1998) should not be seen as mutually exclusive. Contained in TA, based as it is on a psychodynamic approach, is the view that transference and counter-transference are unconscious processes always found in a relationship. The transference concept has been discussed extensively within the TA literature and it is generally acknowledged (Berne, 1964; Moiso, 1985; Hargarden \& Sills, 2002; Erskine, 1991; Novellino, 1984). At the same time, Berne's original critique of a traditional psychoanalytic approach has contributed to efforts to reduce the role of spontaneous regression in therapy and thus the time it requires as well. This has been accomplished by use of various techniques and approaches that encourage active, conscious choices on the part of the client, choices leading to treatment goals expressed in the treatment contract. The emphasis in the TA method has thus shifted from that of long-term efforts involving what are often unarticulated, emotional and chaotic transference relationships to that of observable patterns of behaviour and manifest signs of unconscious communication processes.

The treatment contract achieved represents an important element in the alliance between the client and the therapist. In drawing up such a contract, emphasis is placed on structure, order, clarity and stability so as to give the client a sense of security and a feeling of being able to work effectively with the more deep-lying problems he or she is faced with.

According to Bordin (1979), there are two aspects of alliance, the one an agreement between the client and the therapist regarding the goals and the task of therapy, and the other a special emotional bond between them. Some types of therapy, including TA, place emphasis upon the first, more "rational" aspects of alliance, whereas others emphasize the more "emotional" aspects of it. Our interest here was to study the affective dimension that the second author has described as a "relational technique and relational approach" (Lundh, 2009; Stenlund, 2002) of TA.

\section{Aims of the Study and Questions Posed}

The major goal of the study is to investigate the therapeutic alliance in TA-therapy with the intention of contributing to TA's methodological development. This is done through examining, in the case of transactional analysis group therapy, the affective interaction and the alliance between the therapist and the client. The investigation makes use of both the CCRT method (Core Conflictual Relational Theme method, Luborsky, 1990) and the plan-diagnosis method (Weiss \& Sampson, 1986) - two methods developed within psychodynamic therapy. The questions of central interest are the following:

- How can the affective relational patterns of different clients be characterized?

- To what extent do these patterns manifest themselves in the relations and interactions between the client and the therapist?

- How does the therapist deal with the client when the latter displays behaviour reflective of such relational patterns?

\section{Methods}

Investigative material obtained

The investigative material obtained concerned 10 clients, who took part in transactional analysis group therapy, which they had sought voluntarily, and in which the first author served as therapist. The therapy continued for a year and was divided into 24 sessions. The sessions were videotaped and a transcribed protocol of each session was made. A strategic selection of 10 
sessions was carried out in terms of the phase of therapy involved (beginning, middle and end). In addition, a random selection of 5 of the 10 clients, whose therapy was to be examined in detail, was made.

Because the research was conducted after the therapy had taken place, there were no ethical issues to be considered. The analysis conducted as part of the study had impact on clients only to the extent that the therapist became more aware of client relational patterns and hence ore skilful in future work with those (and other) clients. The clients gave permission for the publication of the transcripts; the names have been changed to maintain confidentiality.

The ethical basis for this study has been examined and approved by Forskningsetikkommittén, Lunds universitet/ The Ethical Research Committee at Lund University (2002).

\section{Instruments}

\section{CCRT method}

Luborsky constructed the CCRT method in 1976 on the basis of the concepts of transference and alliance. A basic conflict theme (a core conflict relational theme, CCRT), according to Luborsky, is an emotional approach or pattern having its roots in the early experiences of the individual in relation to meaningful others. A CCRT can be called forth in any relational situation that reminds one of early childhood experiences of this sort (Luborsky, 1984; Luborsky \& Crits-Christoph, 1988, 1990). Luborsky considers there to be parallels between CCRT and "nuclear script" in Tomkins' (1991) use of that term.

The method involves identifying and analyzing, in the transcripts of tape-recorded therapy sessions, spontaneous accounts by the client of longer or shorter interactions with others, including those with the therapist. Such accounts are termed relational episodes (RE), and those that describe interactions with the therapist are termed enactments. Relational episodes are used to disclose the client's wishes (W) in relation to others, how the client expects others to respond to these wishes (response of others $=\mathrm{RO}$ ) and how the client deals with these wishes (response by self $=\mathrm{RS}$ ). $\mathrm{W}, \mathrm{RO}$ and RS are called components, and typical signs of each are identified and grouped into categories. Categories are first described in a manner similar to how the client tends to express him/herself generally. In this way individual, tailor-made categories are created, specific to each client.

On the basis of sixteen separate studies, Luborsky and Crits-Christoph (1990) put together a list of standard categories for each of the three components (Standard Category Edition 1), in order to make it possible to compare the accounts of different clients with each other, as well as to make the method applicable to studies dealing with therapies of different types. In a second edition of it (Barber, Crits-Christoph \& Luborsky: Expanded Standard Categories Edition 2, 1990), the earlier list was expanded to include $35 \mathrm{~W}, 30 \mathrm{RO}$ and $31 \mathrm{RS}$ categories altogether. In the present study, this second edition served as the basis for translating the tailor-made variations into standard categories. The most frequently encountered combinations of the $\mathrm{W}, \mathrm{RO}$ and RS components constitute nuclear-conflict themes.

Studies have shown that a client's way of relating to others is similar to his or her way of relating to the therapist (Fried, Crits-Christoph \& Luborsky, 1990). W has been found to be rather stable over time, in contrast to RO and RS, which can change considerably (CritsChristoph \& Luborsky, 1990, 1998). Changes in the latter two components have been shown to correlate with changes in the client's general psychic status. A positive therapy outcome has been found to be coupled with a moderate to high level of agreement between the content of the W and RO components in the client's CCRT results and the therapist's assessment of the patient in these terms (Crits-Christoph \& Luborsky, 1988; Crits-Christoph, Cooper \& Luborsky, 1990).

\section{Plan-diagnosis method}

A method for characterizing both the relational pattern of a client and the interaction between the client and the therapist was developed by the Mount Zion Psychotherapy Research Group and Weiss and Sampson (1986). This method is based on the idea that the client's problems can stem from negative experiences in encounters with meaningful others, leading to feelings of guilt, shame, fear and helplessness (=anxiety). Those feelings caused the client to develop what the authors term pathogenic expectations, which in adulthood tend to limit the person's interactions with others. According to Weiss and Sampson, the client "tests" these negative expectations in the therapy situation with the hope that they will not be confirmed, the client having an "unconscious plan" for how his or her pathogenic expectations can be dispelled by being refuted.

This method involves one or more independent observers identifying the pathogenic expectations of the client and his/her "plan" for "testing" them. In the present investigation, situations in which the client implements and "tests" these expectations in working with the therapist are examined. An assessment is made to which extent the therapist confirms or refutes the client's pathogenic expectations being assessed. A variety of studies (Messer, Tischby \& Spillman, 1992, Silberschatz \& Curtis, 1993, Silberschatz, Curtis, Fretter \& Kelly, 1988, Silberschatz, Fretter \& Curtis, 1986) have shown that if the therapist's interventions are true to the client's "plan", this results generally in an improvement on the client's part. 


\section{Coding of the CCRT results}

Coding of the CCRT results was conducted as follows:

- $\quad$ Reading through the results obtained and coding them, this being done by each of the two authors separately;

- Discussing to consensus the final codings to be employed;

- Investigating the reliability of our codings in terms of the degree to which our separate codings agreed (see Interassessment Reliability below).

The overall approach in analyzing the results

The standard procedure for analyzing results obtained by use of the CCRT method was followed. First we identified the relational episodes contained in the therapy protocol of each client. Then, with the help of the coding procedure prescribed, the CCRT (Core Conflictual Relationship Theme) involved in each episode was identified and was coded initially in terms of individual, tailor-made categories applying to the client in question These categories were converted to standard categories (as defined by Barber, Crits-Christoph \& Luborsky, 1990). We then compared each client's treatment contract, coded with use of the standard categories, with their individual, tailor-made CCRTs. Thereafter we identified as enactments those CCRTs that we adjudged to represent pathogenic expectations of the sort the Plan-diagnosis method deals with, and coded the therapist's responses to all "tests" of such expectations, noting in each case whether the therapist confirmed or refuted the client's test of the expectation. All assessments were discussed to consensus. Quantitative and qualitative analyses of the results follow below.

Interassessment reliability

To check the reliability of our assessments in the assignment of relational episodes to the $\mathrm{W}, \mathrm{RO}$ and RS categories, we examined the degree to which the two of us agreed in our initial assignments of this type. We selected randomly five clients (of the 10 who participated) and two of the therapy sessions, one being from an early part of the therapy (session 5) and the other from a later part (session 15). All 10 clients who participated in the study were present in both these sessions.

The procedure we followed was that first the two of us together identified what we adjudged to be relational episodes (RE) for each of these clients in both of the therapy sessions. We then worked independently to assign each of the REs involved to categories of the $\mathrm{W}$, RO or RS component, making use of tailor-made categories of the sort described above. Thereafter, we compared our respective assignments (codings). The results of the codings are summarized in Table 1.

Table 1 shows the total number of categories for 5 clients in two therapy sessions for which both evaluators agree on coding into $\mathrm{W}, \mathrm{RO}$, and $\mathrm{RS}$ components. Evaluators agreed in 149 out of 162 cases, representing an agreement of $92 \%$.

The first author has extensive experience in use of the therapeutic approach in question and thus possesses a "within" perspective. The second author, although having extensive experience with dynamic psychotherapy, has not worked in a practical sense with transactional analysis group therapy and thus has an "outside" perspective, but was able, through discussions we had, to quickly become familiar with this type of therapy. In view of the fact that the first author served as the therapist for all five of the clients, we decided to carry out the coding of the results in such a way that we discussed each coding to consensus, utilizing both an "inside" and an "outside" perspective constructively in this way.

$92 \%$ agreement with each other over the respective codings that the two of us perfmerd separately provided strong support for the assumption that the procedure we adopted for the final codings produced no appreciable biasing of the results. We consider the method of coding we adopted to be superior to one in which the two of us simply coded the material separately. It contributed to the understanding both of us had of how the material could best be coded and allowed the codings to be more exact through an "inner" and an "outer" perspective being confronted with each other in

Table 1. Comparisons of Coding

\begin{tabular}{|c|c|c|c|c|c|c|}
\hline & Session 5 & & Session 15 & & Sessions 5 and 15 & \\
\hline Clients & Total & Agreed & Total & Clients & Total & Agreed \\
\hline Agneta & 17 & 15 & 6 & 6 & 23 & 21 \\
\hline Daniel & 49 & 47 & 6 & 4 & 55 & 51 \\
\hline Erik & 5 & 5 & 19 & 15 & 24 & 20 \\
\hline Harriet & 34 & 32 & - & - & 34 & 32 \\
\hline Barbro & - & - & 26 & 25 & 26 & 25 \\
\hline Sum & 105 & 99 & 57 & 50 & 162 & 149 \\
\hline
\end{tabular}


each case.

\section{Results}

Analysis of the CCRT and Plan-diagnosis results in quantitative terms

Quantitative results are presented in tables 2-7. Tables 2-7 all concern the five randomly selected clients that participated in 10 TA therapy sessions.

Table 2 shows, in 176 RE (table 6), the number of codings of standard categories for each of the three CCRT components registered for the five randomly selected clients in the course of the 10 therapy sessions that were studied. Altogether, 539 standard categories were coded, 136 of them being of the W, 131 of the RO and 272 of the RS type. There are no marked differences between the five clients in the distribution of codings of a particular type.
Table 2: Numbers of CCRT standard categories of the 3 components $W, R O$ and $R S$ for each client.

\begin{tabular}{|c|c|c|c|c|}
\hline Clients & $\begin{array}{l}\text { Wishes } \\
\text { (W) }\end{array}$ & $\begin{array}{l}\text { Responses } \\
\text { of Others } \\
\text { (RO) }\end{array}$ & $\begin{array}{l}\text { Responses } \\
\text { by Self } \\
\text { (RS) }\end{array}$ & Total \\
\hline Agneta & 18 & 19 & 43 & 80 \\
\hline Barbro & 30 & 29 & 61 & 120 \\
\hline Daniel & 26 & 28 & 55 & 109 \\
\hline Erik & 45 & 31 & 72 & 148 \\
\hline Harriet & 17 & 24 & 41 & 82 \\
\hline Total & 136 & 131 & 272 & 539 \\
\hline
\end{tabular}

Table 3: Individual CCRT of most frequently occurring standard categories of the 5 clients components; W, RO and RS (Standard Categories with numberings (NO.) and designations)

\begin{tabular}{|c|c|c|c|c|c|c|}
\hline \multirow[b]{2}{*}{ Agneta } & \multicolumn{2}{|c|}{$\begin{array}{l}\text { Wishes (W) } \\
\text { Standard Categories }\end{array}$} & \multicolumn{2}{|c|}{$\begin{array}{l}\text { Responses of Others (RO) } \\
\text { Standard Categories }\end{array}$} & \multicolumn{2}{|c|}{$\begin{array}{l}\text { Responses by Self (RS) } \\
\text { Standard Categories }\end{array}$} \\
\hline & 34 & To assert myself & 20 & Are controlling & 8 & Am not open \\
\hline & 13 & To be helped & 4 & Are rejecting & 31 & Somatic symptoms \\
\hline \multirow[t]{3}{*}{ Barbro } & 34 & To assert myself & 15 & Hurt me & 22 & Feel depressed \\
\hline & 9 & To be open & 20 & Are controlling & 26 & Feel ashamed \\
\hline & & & 6 & Don't respect me & 27 & Feel anxious \\
\hline \multirow[t]{4}{*}{ Daniel } & 9 & To be open & 20 & Are controlling & 27 & Feel anxious \\
\hline & 1 & To be understood & 8 & Are not trustworthy & 21 & Feel angry \\
\hline & & & 27 & Are angry & & \\
\hline & & & 6 & Don't respect me & & \\
\hline \multirow[t]{3}{*}{ Erik } & 9 & To be open & 12 & Are distant & 27 & Feel anxious \\
\hline & 11 & To be close to others & 20 & Are controlling & 8 & Am not open \\
\hline & 1 & To be understood & 4 & Are rejecting & 22 & Feel depressed \\
\hline \multirow[t]{3}{*}{ Harriet } & 9 & To be open & 20 & Are controlling & 22 & Feel depressed \\
\hline & & & 26 & Are strict & 27 & Feel anxious \\
\hline & & & & & 8 & Am not open \\
\hline
\end{tabular}

The standard categories of a given component for a given client are the two that occurred most frequently for the client in question, or three in the event of a tie. 
Table 4: The treatment contracts of the 5 clients who participated in transactional analysis group therapy.

\begin{tabular}{|c|c|}
\hline Clients & Contract items \\
\hline Agneta & $\begin{array}{l}\text { Spend at least } 1 / 10 \text { of my time in therapy here in the group } \\
\text { Express my anger and direct it outwards rather than being submissive } \\
\text { Put on my raincoat and go out in the woods with my daughter rather than washing clothes }\end{array}$ \\
\hline Barbro & $\begin{array}{l}\text { Be able to admit the mistakes l've made without feeling guilty } \\
\text { Assert myself and express my feelings spontaneously } \\
\text { Stop taking care of others and shielding them from the problems they're faced with, saying "No" to all of this instead } \\
\text { Recognize the patterns that are connected with my mother }\end{array}$ \\
\hline Daniel & $\begin{array}{l}\text { I want to participate in this group without being an observer } \\
\text { Find out what my real emotional needs are rather than being taken upon all the time by my ambitions, my duties } \\
\text { and my work }\end{array}$ \\
\hline Erik & $\begin{array}{l}\text { I want to lead my own life rather than simply showing allegiance to my father and the culture he represents. } \\
\text { Express my feelings and my views on things to my boss and to my work colleagues rather than to simply withdraw. }\end{array}$ \\
\hline Harriet & $\begin{array}{l}\text { Feel relaxed and satisfied rather than being tense and being afraid of everything imaginable } \\
\text { Be conscious of when l'm angry, and express my anger }\end{array}$ \\
\hline
\end{tabular}

The treatment contracts the client and the therapist agreed upon during the first three therapy sessions are shown for each of the five clients in Table 4.Table 5 shows the individual, tailor-made CCRT categories contained implicitly in the treatment contracts of the five clients and the standard categories these were adjudged to correspond to. Also indicated are the two or three that occurred most commonly in the therapy protocols of the client in question. Four of the clients had in common the frequent occurrence of the $W$ category no. 9 ("To be open") and two of the clients the frequent occurrence of the RS category no. 34 ("To assert myself"

As can be seen in Table 6, 44 of the 176 REs involved ( $25 \%$ of them) represent enactments, 35 REs of these $(80 \%)$ agreeing with the clients' individual CCRTs. These 35 REs can be assumed to represent the clients' pathogenic expectations, presented to the therapist as a "test" of the expectation in question in each case. The clients differ in the number of "tests" of this sort they performed, Daniel showing the largest number (11) and Erik the smallest (2).

Table 7 indicates for each client the number of "tests" of this sort for which the therapist's response was unsuccessful (confirming the expectation) and the number for which it was successful (refuting the expectation). The therapist was successful in the majority of the cases $(70 \%)$, with successful responses being highest in the cases of Daniel (82\%) and Erik
(100\%), and lower with Agneta (63\%), Barbro (60\%) and Harriet (62\%).

\section{Qualitative analysis of the therapeutic process}

Parts of the interpretative procedure employed in obtaining the results reported in Table 7 , as well as the affective interaction between the client and the therapist, and both success and failure of the therapist in responding appropriately to "tests" by the client of his/her pathogenic expectations are illustrated in that which follows. Cases in which "tests" by the respective client failed, the therapist's confirming the pathogenic expectation of the client, will be presented first.

Failure: the therapist's responding inappropriately to the client's "test"

Example 1, Agneta

Contract and CCRT. In her contract, Agneta says she wants to learn to express the anger she feels and to create sufficient space for herself. Her CCRT results also indicates her desire to assert herself better and her feeling that others are trying to control her, leading to her isolating herself and experiencing heart palpitations.

Events prior to the test. The therapist turns to Agneta and asks her what she wants to do during the session at hand. 
Table 5: Correspondence between the clients CCRT categories contained in the treatment contracts and in the individual CCRT

\begin{tabular}{|c|c|c|c|c|c|c|c|}
\hline \multirow[b]{3}{*}{ Clients } & \multicolumn{4}{|c|}{ The treatments contracts viewed in terms of CCRT components } & \multirow{3}{*}{$\begin{array}{l}\begin{array}{l}\text { Corresponding } \\
\text { components }\end{array} \\
\text { Component }\end{array}$} & \multirow{3}{*}{$\begin{array}{l}\text { individual } \\
\\
\text { Stand. } \\
\text { Cat. } \\
\text { No. }\end{array}$} & \multirow{3}{*}{$\begin{array}{c}\text { CCRT } \\
\begin{array}{l}\text { Desig- } \\
\text { nations }\end{array}\end{array}$} \\
\hline & \multicolumn{2}{|l|}{ Wishes (W) } & \multicolumn{2}{|l|}{ Response of Self (RS) } & & & \\
\hline & $\begin{array}{l}\text { Individual, } \\
\text { categories }\end{array}$ & $\begin{array}{r}\text { Stand. } \\
\text { Cat. } \\
\text { No. }\end{array}$ & $\begin{array}{l}\text { Individual, } \\
\text { categories }\end{array}$ & $\begin{array}{l}\text { Stand. } \\
\text { Cat } \\
\text { No. }\end{array}$ & & & \\
\hline \multirow[t]{4}{*}{ Agneta } & Asserting myself & 34 & & & To assert myself & 34 & W \\
\hline & Express my anger & 16 & Conforming & 16 & & & \\
\hline & Being liked & 7 & Performing my duties & 16 & & & \\
\hline & Accept my desires & 32 & Please others & 9 & & & \\
\hline \multirow[t]{5}{*}{ Barbro } & Asserting myself & 34 & & & To assert myself & 34 & W \\
\hline & Express my feelings & 9 & & & To be open & 9 & W \\
\hline & Welcoming others & 4 & Feeling guilt & 26 & Feel ashamed & 26 & RS \\
\hline & & & Taking care of others & 9 & & & \\
\hline & & & Protecting others & 9 & & & \\
\hline \multirow[t]{3}{*}{ Daniel } & Express my feelings & 9 & & & To be open & 9 & W \\
\hline & Group participation & 11 & Meeting my responsibilities & 14 & & & \\
\hline & & & Observing & 8 & & & \\
\hline \multirow[t]{2}{*}{ Erik } & Express my feelings & 9 & & & To be open & 9 & W \\
\hline & Being independent & 23 & Withdrawing & 8 & Am not open & 8 & RS \\
\hline \multirow[t]{3}{*}{ Harriet } & Being relaxed and contented & 9 & & & To be open & 9 & W \\
\hline & & & Tense and frightened & 27 & Feel anxious & 27 & RS \\
\hline & Expressing anger & 16 & & & & & \\
\hline
\end{tabular}

Table 6: The total number of REs and enactments for each of the clients and the number of enactments ("tests") that agreed in each case with the corresponding individual CCRTs for the client in question.

\begin{tabular}{lccc}
\hline Clients & RE & Enactments & "tests" \\
\hline Agneta & 35 & 13 & 8 \\
Barbro & 46 & 12 & 10 \\
Daniel & 31 & 12 & 11 \\
Erik & 38 & 2 & 2 \\
Harriet & 26 & 5 & 5 \\
Total & $\mathbf{1 7 6}$ & $\mathbf{4 4}$ & 35 \\
\hline
\end{tabular}

Table 7: The therapist's response to the "test" he was given in each case of a particular pathogenic expectation of the respective client, the numbers of these "tests" that were successful and the number that failed being indicated.

\begin{tabular}{lccc}
\hline Clients & $\begin{array}{c}\text { Number of } \\
\text { tests }\end{array}$ & $\begin{array}{c}\text { Number } \\
\text { failed }\end{array}$ & $\begin{array}{c}\text { Number } \\
\text { successful }\end{array}$ \\
\hline Agneta & 8 & 3 & 5 \\
Barbro & 10 & 4 & 6 \\
Daniel & 11 & 2 & 9 \\
Erik & 2 & 0 & 2 \\
Harriet & 4 & 1.5 & 2.5 \\
Total & 35 & 10.5 & $\mathbf{2 4 . 5}$ \\
\hline
\end{tabular}


Quotation (session 4, RE 1). Agneta: "I feel awfully afraid. I'm having heart palpitations. They came from your forcing me to decide what I wanted to take up today.... begin... (Therapist: $\mathrm{Mm}$ ) It feels almost as though I'd decided to make a speech, that I was forced to do something, as though others were dependent on me in some way (.) Earlier in the week, though, I thought a lot about what I could bring up and that sort of thing. l'd still like to, although I feel afraid..."

\section{Therapist: "Will you only try, or do you plan to do it?"}

Interpretation. The therapist is maintaining control and is trying to steer. His response is at a rational level. He should instead have acknowledged her anxiety and fear, as well as her heart palpitations - and thus have responded at an emotional level so as to give her the possibility of steering on her own, and in that way have provided her the possibility too of asserting herself.

Events following the test. Agneta responds in an abrupt way, saying she wants to talk about that later on in the therapy. Acting as though she's clenching her teeth, she says,..."I was forced to be strong just now."

\section{Example 2, Agneta}

Events just prior to the test. Agneta reports a very disturbing experience she had when she was 14 years old. She was at a maternity clinic where the other women were there to give birth, whereas she was there to have an abortion. She imagined that her father had been there earlier to protect her from disparaging reactions on the part of the clinic's personnel. It turned out, however, that her father had never been there at all and that he himself had spoken disparagingly of her, referring to her as a "whore-devil". Agneta had never had a chance to speak with anyone about this. Two-chair work with Agneta concerned with this experience of hers was begun. Agneta felt herself to have been abandoned and rejected by her father. In this two-chair work the therapist encouraged Agneta to feel anger and express herself openly. At the same time, it appeared that Agneta tended to feel ashamed, rather than to be angry at her father.

Quotation (session 11, RE 7). Therapist: "What do you need to do so as to feel OK, in relation to him, in order to achieve this, in regard to this particular situation? I think you're feeling ashamed, and that it's this that keeps you stuck here, in connection with him, since you don't express...??? As long as you..."

Agneta: "Rationally, so that..."

Therapist: "No, no, we're not talking about being rational. I can hear how you're not expressing at all your being angry at him, but instead you're accepting what he said. It's as though you have guilt that you should atone for. Is that the way you feel it is, can you feel that that's what you're doing, or...? As it is now, you're not angry at him for his having failed to provide you support in that situation."

Agneta: "Yes..."

Therapist: "What do you mean with Yes, what did you say Yes to?"

Interpretation. The therapist is provocative in his tone, almost teasing her. He's "lecturing" to her. Through simply speaking about how things are in that way, he's tending to exert control over her. He should have helped her to overcome her sense of shame, helping her dare to look at the shame she's experiencing and how she's trying to avoid doing so. The therapist is pushing her, getting her to feel angry rather than getting her to experience the sense of shame she has.

Events following the test. Agneta follows the advice the therapist gave her and begins expressing her anger with the help of a batacka (a foam-rubber club), but she has little to say and gives a closed impression. She says she feels "tired and out of breath", yet she says "it feels all right". The therapy stops here.

\section{Example 3, Daniel}

Contract and CCRT. Daniel wants to take part in the group and not simply be an observer. He wants to be in closer contact with his feelings instead of being oriented primarily to matters regarding his duties and his work. A wish to be more open and to be understood is evident in his CCRT. He has expectations of others being angry and of their wanting to maintain control over him, which gives him a sense of anger and anxiety.

Events just prior to the test. Daniel didn't show up at the previous session and failed to notify the group beforehand. He excuses himself, saying he had been mixed up regarding what day it was. Daniel is heckled for this - one of the members of the group saying, "Isn't it usual for it be held on Thursdays?"

Quotation (session 12, RE 8). Daniel: "I got to thinking about this and decided that in any case, even though I've had certain doubts about whether I should continue and that sort of thing, still deep down I've had no serious doubts about wanting to go ahead with it all, and that that's what I want to do. For this reason I was a little nervous when I came, about being criticized for not having shown up last time. Maybe this is how it will be but l'm ready for it in any case."

Therapist: "You'll manage all right."

Therapist: "Where you missed coming the way you did, I wonder what it is that you reject, what is it that you don't, or what is it that you're discounting when you're in the group?"

Daniel: "I'm not discounting the group, but at the end of..." 
Therapist: "But you are."

Therapist: "Now you are here. You're expressing yourself in terms of "possibly" and "perhaps", Maybe there is something in this expressions to consider. You're expressing yourself in a very guarded way."

Daniel: "Yes I think that's true what you said before, and I think I should be doing that."

Therapist: "Should be?"

Daniel: "That's what you said yourself."

Therapist: "Did I do that? I do feel you're listening carefully to what l'm saying." (laughter)

Torgny (a group participant): "We can take a look at the tape."

Daniel: "We can even do that... We can even do that"

Therapist: "Well, do you want to make use of your time here today?"

Daniel: "Yes I do want to do that... but what should I use the time for? I don't have an idea of what I was thinking of before I came, other than the question of why I didn't show up last time. For some time too I've had thoughts about its being on Thursdays, since during the term I couldn't come that day at all, not if it was a Thursday. I'd thought a little bit about what I should say to you, how I should explain that Thursdays aren't possible, why you were such a jerk as to go and change times the way you did..."

Greta (another participant): "We don't need to take that up today. You've gotten the question before, so you don't need, like, to come with arguments."

Daniel: "No that's right."

Therapist: "No it's just a matter of answering the question of whether you want to do something today."

Daniel: "I do want to do something today."

Therapist: "Fine."

Interpretation. The therapist was open and accepting in his tone at the start and tried to help Daniel understand the resistance he was showing, but then he became increasingly demanding and provocative, seeming to be unable to tolerate Daniel's uncertainty and confusion. After the demanding intervention by the therapist, Daniel took up a defensive position in explaining his failure to adhere to what had been agreed upon (his failing to show up the previous time). Daniel probably felt uncertain about how the therapist would react to his not having come the time before. The dialogue took on the character of a fight then. Daniel responds to the therapist's question finally by saying, "I do want to do something today" and the therapist responds by saying "Fine". Yet immediately thereafter the therapist directs his attention at Greta and her problems and continues to work with her.

Events following the test. Daniel remains silent during the remainder of the session, despite having declared that he clearly wants to participate. At the end of the session he says there are two appropriate themes he wants to take up next time - one of them being his having cried when he had had to put his fiancé's sick dog to death and the other being to discuss further the matter Greta had brought up - of her wanting to be closer to her children and have fun with them, rather than being nagging and unpleasant in interacting with them

Success: the therapist's responding appropriately to the client's "test"

\section{Example 1, Daniel}

Events prior to the test. Daniel listened to a tape recording of an earlier session and found he had been angry because he defended himself by overanalyzing things, and at the same time he felt threatened by a comment the therapist had made,

Quotations (session 19, RE 10) (shortened and simplified somewhat for purposes of clarity): Therapist: "What was it I said?" Daniel: "You said there was an ugly incident of mine I could present, and that those in the group felt I should take things up more openly.

Therapist: "Yes."

Daniel: "But I did present the incident."

Therapist: "What did you experience as a threat?"

Daniel: "That I felt, damn it, he has some sort of key or something he can use to break through my defences, if he's nasty enough to do it."

Therapist: "Yes." Daniel: "I keep thinking about how it is I defend myself." Therapist: "Do you know that you're defending yourself?"

Daniel: "Yes, before I've managed to do anything I think of how I'll defend myself when I'm completely prepared for it. I then sometimes think of how I'm easily alarmed and can exaggerate the dangers I'm faced with, but actually I don't think I do."

Therapist: "What is it you're defending yourself against?"

Daniel: "I don't really want to look at what's behind it all, and can't seem to think things through completely. I feel 
as though I ought to have something to say about it all, but it's as though I'm faced with a bottomless pit, one that I can't find my way through. It's as though my thoughts simply stop."

Therapist: "Yes."

Daniel: "But it's not completely so. I'm certain that I'm defending myself against something, that there's a very strong wall set up against it all, a wall I can't seem to break through."

Therapist: "Here's how things are, that's what's so fantastic about people. You know everything here, what you're defending yourself against, what you're afraid of, what you feel threatened by, you know all of that."

Daniel: "Yes." Therapist: "But then if you want to talk about it, or express it in some way, or if you want to avoid it, or whatever, that's another matter. There's nothing I can do with you that you don't already know about."

Daniel: "No." Therapist: "I can't break through your defences, there's no way." Daniel: "I become frightened when I realize, as I've tried to say, that I even defend myself against defence."

Therapist: "I understand your feeling threatened by the fact that, when I'm about to do something, you can feel forced to let go of or to reveal certain things."

Interpretation. The therapist first failed to realize the depth of the feeling Daniel had of being threatened and was close to trying to make him feel ashamed of having described the therapist as threatening, by teasing him about it a bit, but in the end the therapist comprehended how things were and repaired their alliance.

Events following the test. Daniel continues to take up his difficulties in opening himself up in the group. After a time, he says he feels less nervous than before, remarking "my nervousness has begun to flutter away". He expresses in the current session his feeling of being completely there and a sense of being genuine in what he does.

\section{Example 2, Daniel}

Quotation (session 19, RE 11). (Slight simplifications were made here too for purposes of clarity.) Daniel: "Yes, but I'm wondering why you're smiling the way you are."

Therapist: "How do you feel?"

Daniel: "I was set back a little by the way you smiled. I don't know what it was, but I felt a little bit irritated at it."
Therapist: "Yes, I smiled feeling that it was somewhat exaggerated, and realizing that you were experiencing it that way."

Daniel: "That's what I felt, that it wasn't completely as it should be."

Therapist: "I was being ironic. What do you think of that."

Daniel: "About being ironic in general?"

Therapist: "No, about what I did.” (laughter)

Daniel: "No, it was okay..." (laughter generally and small talk).

Daniel: "It was dirt-cheap too. It didn't cost much of anything. In that connection, I like it a lot, if it gets me to stand up for what I want. I realize very much that I need to do that, and take advantage of the little bit l've gotten here, things aren't neutral any more, but I feel something for it all. That's really important, as I see it. Feeling for things..."

Therapist: "I don't want to seem rejecting of you to make you feel that way." Daniel: "That I understand perfectly well. It doesn't seem that way at all. I sensed that I understood the meaning of feeling for things generally."

\section{Therapist: "Good. How do you feel now?"}

Interpretation. Daniel dares to question the approach the therapist takes and to test him still further, possibly because the therapist, in connection with Daniel's earlier testing of him, repaired and thus strengthened the alliance between them. In the case considered here, Daniel becomes upset at the therapist's smiling at him, making him feel that he was being mocked. The therapist again repairs the alliance through admitting he had done it in ironic intent. The therapist is able to show that even this seeming triviality is meaningful - that Daniel dared to open himself up in connection with it The repair the therapist performs then makes the contact between them still closer than before.

Events following the test. Daniel continues to explore and to give outward expression for feelings of different sorts that develop within him. He tells both of being fearful and of being sad, but also of being curious about the various feelings he experiences. He also dares to engage in two-chair work. When that has been completed, he says "I feel alert and full of energy, like a young horse that kicks up its legs, at the same time that I'm a little nervous, but that's not so important...then I feel very much surprised, I can hardly believe that the whole thing works, that it really functions, but it does." 


\section{Example 3, Barbro}

Contract and CCRT. Barbro describes in her contract her wish of being more receptive of others without feeling any sense of guilt for that, of asserting herself better and of expressing more openly what she feels. In her CCRT one can note, just as in her contract, her wish to assert herself and to be more receptive of others, and in addition a fear she has of others trying to control her and of their failing to respect her and possibly harming her, this leading to her feeling depressed, ashamed and fearful.

Events prior to the test. Barbro reports on her relationship with her mother, whom she feels strongly bound to and at the same time fearful of. She tells of her efforts to do what her mother expects and of her endeavoring to be liked by her mother. In the therapy sessions she is encouraged to work on this in a two-chair situation, yet she finds this uncomfortable, saying she experiences it as being foolish and more like a theatrical performance, and that in doing so it is as if she were trying to be a good client and nothing else. Accordingly, the two-chair work undertaken is broken off. She continues then on her own initiative in taking up a dream she had, in which she imagined herself as a small child seeking help. Her reporting of the dream has a strong emotional tone.

Quotation (session 4, RE 4). Barbro: "I need someone to take care of me." Therapist: "Mm" Barbro: "I'm unhappy, I feel so lonely."

Therapist: "Mm. What's happening around you?"

Therapist: "You don't need to hide." (Barbro cries) "I'm saying to you again: You don't need to hide. You're free to ask for whatever you want."

Barbro: "The best way to get her (her mother, that is) to like me is to hide." Therapist: "Say: I don't need to hide. I want to say to you that..."

Barbro: "I don't need to hide."

Therapist: "I want to say to you that..."

Barbro: "I want you to, I want you to take care of me. (she cries).I want to be a small child too."

Therapist: "You have a right to demand that. When you're a small child you have the right to demand that. To be allowed to be small and... How do you feel?"

Barbro; "I don't know. I do feel calm, though."

Therapist: "I believe you. It's good that you're speaking about what you need. Is there anything you need right now?"

Barbro': "I need someone who..."
Therapist: "Is there someone you want to ask something of, ask for something?" Barbro: "It's so difficult..." (she giggles)

Therapist: "Yes it can be."

Barbro: "Yes, I want to sit with you for awhile."

Therapist: "With me? Mm...I'll come over to you instead, it's easier. I'll come over to you so that we can...Is it time for the pause now? That means I won't get any coffee then."

Interpretation. At the beginning the therapist had tried to push a little to get her to do two-chair work, but she experienced it as being foolish (ashamed), feeling it was like a theatrical production. When the therapist then affirmed and responded to Barbro's suggesting, on her own initiative, that she report on a dream she had, she gets the opportunity to assert herself and steer the work with her therapy herself. Her reporting on the dream leads to her expressing her unhappiness openly, The therapist responds in a concrete way to her wish of closeness by sitting down next to her. He helps her "bite the head off of" feeling ashamed, upholding the desire she had expressed, instead of withdrawing.

Events following the test. Barbro expresses a sense of relief. She says: "It feels good now. I didn't think l'd dare to ask that of you, l'd been so afraid of you before."

\section{Discussion}

On the basis of our results in investigating clienttherapist interactions in transactional analysis group therapy we conclude that the affective dimension in the therapeutic alliance in this form of therapy plays a considerably stronger role than is stated in our assumption that TA mainly is emphasising the rational dimension of the alliance. Also, despite the efforts being made in the use of some TA methods to limit or avoid the occurrence of transference phenomena, the results we obtained showed transference to take place to a degree comparable to that which can be observed in a study in psychodynamic therapy by Stenlund (2002), where achieving transference is aimed at.

Each of the clients "tested" the therapist. The 5 clients who were studied appeared to differ considerably in the degree of transfer that occurred. Daniel, for example, "tested" the therapist many more times than Erik did. An explanation for this can be that there were marked differences between them, as reflected in their respective CCRTs, in their manner of dealing with a stressful situation, in terms of fight or flight. Daniel's CCRT results point to a strategy characterized by fight, his critically observing and questioning things very much, whereas Erik appeared to avoid confrontations and to endeavour to adjust to things as they are, a strategy in this sense of flight. 
To a large extent, the therapist appears to have responded appropriately to the "tests" in the therapy situation that the clients made of their pathological expectations. How things turned out, both in connection with the therapist's responding appropriately and with his responding inappropriately emphasize the importance of the affective dimension in the therapeutic alliance. The therapist, who had knowledge about transference but also had the intention to reduce it, appears to have worked intuitively with transference in a way that strengthened the alliance with some clients. This is in line with Tomkins (1962, 1963, 1991, 1992), who regards affects as the primary motivational force. The results of the study point to the fact that affective communication is so basic in human communication that it's not possible to exclude or reduce.

The qualitative analysis of portions of the therapy protocols that were presented here suggests there to be a conflict between different therapeutic approaches, one that can be related to Lundh's (2009) reasoning in considering the therapeutic relationship to represent a "technique". Lundh regards this aspect of the therapeutic relationship as always being present, though its content can vary. He contrasts an empathetic-validational approach with a steering-influencing approach, considering the former to concentrate more on the inner world of the client and to emphasize listening and the achieving of empathetic understanding more than the latter approach does, which aims at encouraging thinking and concrete behaviours of particular types. In our study the therapist appeared to have certain difficulties in balancing the use of these two differing approaches, where the TA technique, as conventionally described, is more in line with the steering-influencing than with the empathetic-validational approach. Employing the TA technique as a strategy for driving the therapeutic process forward was found to sometimes lead to a setback for the process intended and even to a stoppage of it.

Agneta exemplifies this. In her CCRT she expresses the wish of being more open rather than being reserved and inhibited, as she often tends to be. In two-chair work she obviously has great difficulties in letting go, turning to the therapist and saying that what she is doing does not seem natural and seems somewhat foolish. The therapist does not take heed of this, brushing aside her sense of embarrassment, and thus not helping her to deal with the situation. His efforts to get her to continue with the two-chair work result finally in her discontinuing it entirely.

Sandell (2009) takes Lundh's line of reasoning regarding the therapeutic relationship constituting a technique a step further, maintaining that the distinction should also be made between surface and depth - i.e. between what is manifest, readily visible and obvious, and what is latent, subtle or implied. Sandell terms the more superficial aspect 'interactions" and the deeper one "relationships". Sandell thus emphasizes the subjective and individual or personal aspects of the interaction between the client and the therapist, whereas Lundh focuses on the more technical or professional aspects of it. It seems sensible to assume that an "empathetic-validational" approach places greater emphasis on "relationships" and a "steering-influencing" approach greater emphasis on "interactions".

In the long run there can be a risk of a largely exclusive schooling in the use of a single therapeutic approach being disadvantageous to therapeutic work. A therapist who places one-sided emphasis upon the therapeutic relationship, i.e. on feelings at the more unconscious level, can lose interest in concrete changes in manifest behaviour. In contrast, a therapist who employs a directive goal-oriented approach and lays emphasis on the client's concrete and more conscious behaviours, and on the purely interactional side of contact with the client, can lose interest in the tacit inner processes involved. Although one might easily assume these two approaches to by nature be contradictory, this need by no means be the case, provided the therapist has sufficient simultaneous attentional capacity and the ability to attend to contradictory elements in the therapy situation.

Considering again the case of Agneta, in which the therapist fails to take account of the inner thoughts of the client and to interpret them properly - their interaction with one another and her conceptions of things - so that their "relationship" is not taken adequate account of, one can note that their "interaction" gets nowhere. There the more superficial relationship involved, though aimed at promoting a process of change, is largely a hindrance to their effective interaction and thus to the success of both the inner and the outwardly manifest process of change which is sought. In the case of Barbro, the therapist lays emphasis on the "relationship" between them through responding appropriately to her emotional message. She speaks of feeling calm, but the therapist asks her nevertheless whether there is anything she feels in need of just then, acting on the basis of his conception that she feels in need of something. Barbro responds by declaring her wish of sitting next to him, but at the same time, by giggling, delivers the message of her being embarrassed at this. The therapist then takes the initiative and performs the concrete act of approaching her. In so doing, he acts in line with his understanding of what Barbro was communicating, that she was embarrassed and wanted him to take the initiative. In psychotherapy generally, particularly within the dynamic school of it, but also within TA, one is often schooled in not taking such initiative, the therapist being advised to wait and let the client take the initiative needed to satisfy his or her needs.

Use of an integrative multidimensional rather than a strict method-true approach in the therapeutic encounter is something we like to recommend. An important therapeutic skill can be seen to be that of the therapist's having knowledge of a variety of different methods and approaches, particularly when this is combined with a high degree of flexibility and simultaneous attentional 
capacity, which can also contribute to the therapist's ability to repair mistakes and misunderstandings (Safran \& Muran, 1998, 2000). This latter ability is an important and perhaps necessary one for the therapist to possess, regardless of what therapeutic method or approach he or she employs. This allows hindrances and breaks in alliance to be bridged over and to be avoided.

Obtaining knowledge of the curative mechanisms that are effective in the therapeutic process is a challenge for research in psychotherapy generally. The complexity of the interaction between the therapist and the client makes this area of research a difficult one in methodological terms. The investigative material can readily become so extensive that quantitative limitations need to be placed on it. The data basis for our study is very limited as it only included one group therapy involving five invested clients and one therapist. Although this places very definite limits on the generalizability of the results, it does provide the possibility of examining in some detail the interaction between the client and the therapist and of gaining considerable insight into the therapeutic relationships involved. The alliance between the therapist and the client is important in all forms of therapy. Our results can be seen as contributing to an understanding of the dynamics between the rational and emotional alliance, as well as to the knowledge of psychotherapy generally and to the methodological development within it.

In the present investigation we examined details of therapy sessions that were studied with qualitative methods, involving interpretation of the content of what the therapist and the client said. These methods are well adapted to clinical practice and thus to use by therapists in a clinical context.

Methods for investigating the phenomenon of alliance have been developed primarily within the area of dynamic psychotherapy research. Our having investigated TA therapy here with use of methods having a psychodynamic reference is of clear advantage in that our results are able to show that the affective dimension found in alliance is of relevance not only to psychodynamic but also to TA therapy. Alliance can thus be considered to represent a "common" and curative factor in both forms of therapy, perhaps too in therapies in general.

We decided in our study to take up specifically the interaction between the individual client and the therapist without examining the effects the group has on the client's interaction with the therapist. We have assumed that, since in TA therapy of this type the therapist concentrates on the individual client and not on the group, the group dynamics within the group which was also there played no more than a subordinate role in determining how alliance between the therapist and the client developed. This may be an area for further study.
It is worthy of note that that the group in question had a male therapist and that the clients consisted of eight women and two men. In a group-dynamic perspective, this should be relevant both to the interactions between clients and to their relation to the therapist, and may also be an area for further study.

The aim of our study was to investigate whether emotional aspects of the alliance between the client and the therapist play an appreciable role in a form of therapy in which such aspects are not generally considered to represent a factor of particular note. This applies for the investigated TA therapy, in which rational aspects of alliance are emphasized. The results of our study showed affective dimensions of alliance to play a considerably stronger role than would be expected if alliance were based on a predominance of rational considerations. It appears that emotional aspects of the alliance between the client and the therapist represent an important factor in TA therapy. Results of the study thus appear to be of clear clinical relevance to transactional analysis psychotherapy.

Further research on the psychotherapeutic process is needed to obtain more adequate insight into the complex phenomena involved. Alliance is important in this connection. Its importance may often be underestimated.

Roland Johnsson is a Teaching and Supervising Transactional Analyst (Psychotherapy) and can be contacted on roland@livsterapi.se

Gunvor Stenlund PhD is Senior Lecturer, Department of Psychology, Lund University.

\section{References}

Barber, J.P., Crits-Christoph P., \& Luborsky, L.(1990). A guide to the CCRT standard categories and their classification. In $\mathrm{L}$. Luborsky \& P. Crits-Christoph (Red.), Understanding transference. The core conflictual relationship theme method (ss. 37-49). New York: Basic Books.

Berne, E. (1958) Transactional Analysis: A new and effective method of group therapy. The American Journal of

Psychotherapy, 12, 735-753

Berne, E. (1961) Transactional Analysis in Psychotherapy. New York: Grove Press

Berne, E. (1963) The Structure and Dynamics of Organizations and Groups. New York: Grove Press

Berne, E.. (1964) Games people play. The psychology of human relationships. New York: Grove Press

Berne, E. (1966) Principles of Group Treatment. New York: Grove Press

Berne, E. (1972) What Do You Say After You Say Hello? New York: Grove Press 
Bordin, E. S. (1979). The generalizability of the psychoanalytic concept of the working alliance. Psychotherapy: Theory, Research and Practice, 16, 252 - 260.

Clarke, K. M. \& Greenberg, L. S.(1986). Differential effects of the Gestalt two-chair intervention and problem solving decisional conflict. Journal of Counselling Psychology, 33, 11-15

Crits-Christoph P., Cooper, A., \& Luborsky, L.(1990). The measurement of accuracy of interpretations. In L. Luborsky \& P. Crits-Christoph (Red.), Understanding transference. The core conflictual relationship theme method (ss. 173-188). New York: Basic Books.

Crits-Christoph P., \& Luborsky, L.(1988). Application of the CCRT: A measure of adequacy of therapist's interpretation and measure of patient's self-understanding. I H. Dahl, $\mathrm{H}$. Kächele \& H. Thomä (Red.) Psychoanalytic process research strategies (ss. 117-128). New York: Springer Verlag.

Erskine, R. (1991). Transference and transactions: critiques from an intrapsychic and integrative perspective. Transactional Analysis Journal 3(3), 17-18

Forskningsetikkommittén (2002) Protokoll 104-2 från Forskningsetikkommittén på Lunds Universitets sammanträde 2002-03-20 (Protocol 104-2 from the Ethical Research Committee of Lund Universities meeting 2002-03-20)

Fried, D., Crits-Christoph P., \& Luborsky, L.(1990). The paralle of the CCRT for the Therapist with the CCRT for Other People. I L. Luborsky \& P. Crits-Christoph (Red.), Understanding transference. The core conflictual relationship theme method. New York: Basic Books.

Frank, J. D. \& Frank, J. B. (1991). Persuasion and healing: $A$ comparative study of psychotherapy ( $3^{\text {rd }}$ ed.). Baltimore: John Hopkins University Press

Goulding, R. \& Goulding, M. (1979) Changing lives through Redecision Therapy. New York: Grove Press

Greenberg, L. S., Rice, L. N. \& Lietaer, G. (1993). Facilitating emotional change. New York: Guilford

Hargaden, H. \& Sills, C. (2002). Transactional Analysis: a relational perspective. Hove: Brunner-Routledge

Hill, C.E. \& Lambert, M.J. (2004). Methodological issues in studying psychotherapy processes and outcomes. Bergin \& Garfield's Handbook of psychotherapy and behavior change.

Henry, W.P., Strupp, H.H., Schacht, T.E., \& Gaston, L. (1994). Psychodynamic approaches. I

A.E. Bergin \& S.L. Garfield (Red.): Handbook of Psychotherapy and Behavior Change (ss. 467-508). New York: Wiley \& Sons.

Horvath, A.O., \& Bedi, R.P. (2002). The alliance. I J.C. Norcross (Red). Psychotherapy Relationships that Work. Oxford, England: Oxford University Press, 37-69.

Horvath, A. O., \& Symonds, B. D. (1991). Relation between working alliance and outcome in psychotherapy: A metaanalysis. Journal of Counseling Psychology, 38, 139-149
Lambert MJ, \& Ogles BM (2004). The efficacy and effectiveness of psychotherapy. Bergin and Garfield's handbook of psychotherapy and behaviour change. ( $5^{\text {th }}$ ed.) New York, Wiley, p. 139-93.

Luborsky, L. (1984). Principles of Psychoanalytic psychotherapy. A manual for supportive-expressive treatment. New York: Basic Books.

Luborsky, L. (1990). The Convergence of Freud's Observations about Transference and the CCRT evidence. I L. Luborsky \& P. Crits-Christoph (Red.), Understanding transference. The core conflictual relationship theme method. New York: Basic Books.

Luborsky, L., \& Crits-Christoph, P. (1990). Understanding Transference: The Core Conflictual Relationship Theme Method. New York: Basic Books.

Luborsky L, \& Crits-Christoph P. (1998). Understanding Transference: The Core Conflictual Relationship Theme Method, ( ${ }^{\text {nd }}$ ed.) Washington, DC, American Psychological Association.

Lundh, L-G. (2006) Metaperspektiv på Psykoterapin del I. Psykologtidningen, $n r$ 6, 19-22.

Lundh, L-G. (2006) Metaperspektiv på Psykoterapin del II. Psykologtidningen, $n r$ 7, 19-22

Messer, S.B., Tishby, O., \& Spillman, A. (1992). Taking context seriously in psychotherapy research: Relating Therapist intervention to Patient progress in Brief Psychodynamic Therapy. Journal of Consulting and Clinical Psychology, 60, 678-688.

Moiso, C. (1985). Ego states and transference, Transactional Analysis Journal 15(3), 194-201

Novellino, M. (1984). Self-analysis of counter-transference. Transactional Analysis Journal, 14(1) 63-75

Ohlsson, T. (1998). Two ways of doing regressive therapy: Using Transactional Analysis Proper and using expressive techniques, Transactional Analysis Journal 28, 83-87

Rogers, C. (1961). On becoming a person. London: Constable Safran, J D \& Muran, J C (1998). Understanding alliance ruptures and therapeutic impasses. Negotiating the therapeutic alliance (ss. 72 - 108). London: Guilford Press.

Safran, J. D. \& Muran, J. C. (2000). Negotiating the therapeutic alliance: A relational treatment. London: Guilford Press.

Sandell, R. (2009). Den terapeutiska relationen- faktisk interaktion eller inre representation. Psykologtidningen, $n r 9$, $12-16$.

Silberschatz, G. (1986). Testing Pathogenic Beliefs. I J. Weiss \& H. Sampson \& the Mount Zion Psychotherapy Research Group: The Psychoanalytic Process. Theory, Clinical Observations, and Empirical Research (256-266). New York: Guilford Press.

Silberschatz, G., Curtis, J.T. (1993). Measuring the Therapist's Impact on the Patient's Therapeutic Progress. Journal of Consulting and Clinical Psychology, 61, 403-411. 
Silberschatz, G., Fretter, P.B., \& Curis, J.T. (1986). How do Interpretation Influence the Progress of Psychotherapy? Journal of Consulting and Clinical Psychology, 54, 646-652.

Stenlund, Gunvor (2002). Psykodynamisk korttidsterapi. En intensivstudie av samspel, Förändring och utfall. Lund: Bloms i Lund Tryckeri AB (ss. 11 - 113).

Tomkins, S.S. (1962). Affect/Imagery/ Consciousness. Vol. 1: The positive affects. New York: Springer.

Tomkins, S.S. (1963). Affect/Imagery/ Consciousness. Vol. 2: The negative affects. NewYork: Springer.

Tomkins, S.S. (1991). Affect/Imagery/ Consciousness. Vol. 3: The negative affects: anger and fear. New York: Springer.
Tomkins, S.S. (1992). Affect/Imagery/ Consciousness. Vol. 4: Cognition: duplication and transformation of information. New York: Springer.

Wampold, B.T. (2001) The Great Psychotherapy Debate: Models, Methods, and Findings. New Jersey: Lawrence Erlbaum Associates

Weiss, J., \& Sampson, H., \& the Mount Zion Psychotherapy Research Group. (1986). The Psychoanalytic Process. Theory, Clinical Observations, and Empirical Research. New York: Guilford Press. 